\title{
Deteksi Dini Anak Gangguan Spektrum Autisme dan Interaksinya dengan Orang Tua dan Saudara Kandung
}

\author{
${ }^{1}$ Gladys L. Kandouw \\ ${ }^{2}$ Anita Dundu \\ ${ }^{2}$ Christofel Elim
}

\author{
${ }^{1}$ Program Studi Pendidikan Dokter Fakultas Kedokteran Universitas Sam Ratulangi Manado \\ ${ }^{2}$ Bagian Psikiatri Fakultas Kedokteran Universitas Sam Ratulangi Manado \\ Email: anggelsglk@gmail.com
}

\begin{abstract}
Autism spectrum disorder is a development disorder that appears before the age of three years old. It has three types of characteristic, inter alia social interaction. Children with autism spectrum disorder need interaction with their families or close-related people because they interact with their own styles. They need people who can understand what they want and their parents have the dominant roles. This study was aimed to obtain the interaction between children with autism and their siblings as well as their parents. This was a descriptivequantitative study with a cross sectional design. The results showed that there were 64 children with autism spectrum disorder; most were 7-10 years old. Males $(59.6 \%)$ were more common than females $(40.4 \%)$. There was interaction between children with autism and their siblings and parents which manifested as raging violently and crying abruptly. Conclusion: Children with autism spectrum disorder were dominantly male and aged 7-10 years old. The interaction between children with autism and their siblings and parents manifested as raging violently and crying abruptly.
\end{abstract}

Keywords: children, autism, interaction, parents, siblings

\begin{abstract}
Abstrak: Gangguan spektrum autis adalah gangguan perkembangan yang muncul sebelum usia tiga tahun dengan 3 tipe karakteristik; salah satu diantaranya yaitu interaksi sosial. Anak gangguan spektrum autisme membutuhkan interaksi dengan orang-orang terdekat karena anak-anak tersebut berinteraksi dengan gayanya sendiri. Orangtua memiliki peran dominan dan merupakan orang yang paling dapat mengerti dan dimengerti oleh anak gangguan spektrum autisme. Penelitian ini bertujuan untuk mengetahui interaksi anak autisme dengan saudara kandung dan orang tua. Jenis penelitian ialah deskriptif-kuantitatif dengan desain potong lintang. Hasil penelitian memperlihatkan bahwa dari total 64 anak autisme yang diteliti, terbanyak berusia 7-10 tahun yaitu 30 anak. Gangguan ini lebih banyak ditemukan pada laki-laki $(59,6 \%)$ dibandingkan perempuan $(40,4 \%)$. Terdapat interaksi antara anak autisme dengan saudara kandung dan orang tua berupa mengamuk dan menangis secara tibatiba. Simpulan: Anak gangguan spektrum autisme terbanyak berjenis kelamin laki-laki dan usia 7-10 tahun. Interaksi dengan keluarga berupa mengamuk dan menangis secara tiba-tiba.
\end{abstract}

Kata kunci: anak, autisme,interaksi, orang tua, saudara kandung

Manusia adalah makhluk sosial yang dalam kehidupannya tidak dapat lepas dari interaksi, sosialisasi, dan komunikasi. Komunikasi menjadi sangat penting karena dengan berkomunikasi seseorang akan dapat mengungkapkan apa yang mereka inginkan dan apa yang mereka harapkan dari orang lain dalam aktivitasnya. ${ }^{1}$ Walaupun komunikasi antar manusia di bumi sudah sangat mudah, masih terdapat sekelompok manusia yang tidak mampu berkomunikasi dengan orang terdekat sekalipun. Mereka hidup dalam 
dunianya sendiri, kemampuan untuk mengadakan hubungan sosial dan membina relasi sosial sangat terbatas, tidak terjadi kedekatan dengan orang lain, serta menunjukkan kegagalan akrab dengan orang lain baik orang tua, saudara kandung, atau orang lain. Interaksinya hanya terhadap hal-hal yang menarik baginya; mereka ini mengalami gangguan yang dinamakan autisme. ${ }^{2}$ Gangguan spektrum autis menurut World Health Organization's International Classification of Diseases (ICDI10) didefinisikan autisme khususnya childhood autism sebagai adanya keabnormalan dan atau gangguan perkembangan yang muncul sebelum usia tiga tahun.

Terdapat 3 tipe karakteristik gangguan spektrum autisme yang terjadi di tiga bidang yaitu interaksi sosial, komunikasi, dan perilaku yang diulang-ulang. Pravalensi anak gangguan spektrum autisme di bawah usia 12 tahun sebesar 2-5 kasus per 10.000 anak $(0,02-0,05 \%)$. Jika retardasi mental berat dengan ciri autistik dimasukkan, angka dapat meningkat sampai setinggi 20 per 10.000 . Pada sebagian besar kasus gangguan spektrum autisme pada anak di mulai sebelum anak berusia 36 bulan akan tetapi terkadang orangtua tidak menyadari adanya gangguan tersebut. ${ }^{3}$

Data United Nations Education Scientific and Cultural Organization (UNESCO) tahun 2011 mencatat sekitar 35 juta orang penyandang autisme di dunia, yang berarti rata-rata 6 dari 1000 orang di dunia mengidap autisme. Begitu juga dengan penelitian dari Centers of Disease Control and Prevention (CDC) Amerika Serikat pada tahun 2002 terdapat 1 diantara 150 anak, kemudian pada tahun 2008 menjadi 1 diantara 88. Di Indonesia sampai saat ini belum ada angka pasti mengenai jumlah penyandang autisme, ${ }^{4}$ akan tetapi hasil penelitian Judarwanto tahun 2015 diperkirakan satu per 250 atau terdapat kurang lebih 12.800 anak penyandang autisme atau 134.000 penyandang spektrum autisme di Indonesia. Anak gangguan spektrum autisme memerlukan orang-orang yang dapat memahami dan mengerti apa yang diinginkan anak tersebut dan orangtua memiliki peran dominan dan merupakan orang yang paling dapat mengerti dan dimengerti oleh anak gangguan spektrum autisme. Penelitian ini bertujuan untuk mengetahui gambaran secara kualitatif interaksi sosial timbal balik antara anak autis dengan orang tua dan saudara kandung.

\section{METODE PENELITIAN}

Jenis penelitian ini ialah deskriptifkuantitatif untuk mengetahui interaksi anak autisme dengan saudara kandung dan orang tua dengan desain potong lintang. Pengumpulan data melalui kuisioner, kemudian dilakukan penelitian lanjutan berupa penelitian kualitatif.

Studi kualitatif yang disajikan tergolong dalam bentuk studi kasus. Studi kasus dalam penelitian ini tergolong dalam studi intrinsik dan pengumpulan data berupa wawancara mendalam yang berlangsung di SLB Khusus Autis Permata Hati, SLB Khusus Autis Hizkia, SLB AGCA Centre Manado, SLB GMIM Nazareth Tuminting, SLB B/C Kristen Emmanuel, SLB A Bartemeus, SLB YPAC MANADO, SLB Tuna Grahita St. Anna, Autism Centre Manado, dan Sentra Pendidikan Anak Berkebutuhan Khusus Amadeus.

Waktu penelitian berlangsung selama 3 bulan dari bulan November 2015 sampai Januari 2016. Dari sampel yang terkumpul , dipilih 2 orang tua yang bersedia untuk dilakukan penelitian kualitatif. Variabel penelitian ini yaitu interaksi anak autis, saudara kandung, dan orang tua.

\section{HASIL PENELITIAN}

Pada penelitian ini didapatkan sampel anak autisme sebanyak 47 anak, terbanyak pada usia 7-10 tahun (Tabel 1). Sampel berjenis kelamin laki-laki lebih banyak daripada perempuan (Tabel 2).

\section{Hasil Penelitian Kualitatif}

Kegiatan penelitian kualitatif untuk sampel pertama dilakukan dirumah responden di daerah Tuminting Manado, tanggal 20 Januari 2016, pukul 19.30 WITA. Di rumah tersebut dijumpai ayah, ibu, dan anak dengan gangguan spektrum autisme. 
Tabel 1. Distribusi anak autisme berdasarkan usia

\begin{tabular}{ccc}
\hline Usia & Jumlah & \% \\
\hline 3 & 2 & 4,25 \\
4 & 3 & 6,38 \\
5 & 1 & 2,12 \\
6 & 3 & 6,38 \\
7 & 6 & 12,76 \\
8 & 9 & 19,14 \\
9 & 8 & 17,02 \\
10 & 7 & 14,89 \\
11 & 4 & 8,51 \\
12 & 4 & 8,51 \\
Total & 47 & 100 \\
\hline
\end{tabular}

Tabel 2. Distribusi anak autisme berdasarkan jenis kelamin

\begin{tabular}{lcc}
\hline & \multicolumn{2}{c}{$\begin{array}{c}\text { Jumlah anak } \\
\text { autisme }\end{array}$} \\
\hline Jenis kelamin & N & \% \\
Laki-Laki & 28 & 59,6 \\
Perempuan & 19 & 40,4 \\
Total & 47 & 100 \\
\hline
\end{tabular}

Wawancara dilakukan di ruang tamu responden. Untuk sampel kedua dilakukan di dalam ruangan kerja kantor responden yang terletak di daerah Jl. Diponegoro Manado tanggal 21 januari 2016, pukul 12.30 WITA. Penelitian kualitatif ini dilakukan terhadap 2 orang responden yang sebelumnya sudah mengisi kuesioner. Responden pertama sopan dan terbuka saat dilakukan wawancara begitu juga dengan responden kedua.

\section{BAHASAN}

\section{Dinamika Kasus 1 dan Bahasan}

SP, seorang anak perempuan berusia 9 tahun, beragama Kristen Protestan, anak pertama dari dua bersaudara. Adiknya berusia 6 tahun yang masih bersekolah di sebuah sekolah dasar. Sejak lahir SP tinggal dengan kakek dan neneknya yang beralamat di Perumahan Puri Indah Permai Malalayang. SP memiliki interaksi dengan kakek, nenek, dan adiknya yang berusia 6 tahun. Nenek SP sering membuatkan makanan kesukaan SP yaitu nasi goreng sehingga SP senang bercanda dengan neneknya dan saat SP ingin mengungkapkan keinginanya SP suka memegang wajah neneknya dan dihadapkan ke wajahnya dan kemudian berbicara untuk mengungkapkan keinginannya. Keinginan SP pasti dituruti oleh kakeknya, salah satunya saat SP meminta cemilan di warung yang mengandung coklat, susu, dan bahan pengawet, bahkan SP sendiri sering meminum kopi yang dibuatkan nenek untuk kakeknya. Setelah SP mengonsumsi kopi itu gejala yang dialami malah memburuk dan membuat SP tiba-tiba menangis.

Ritmie dan Fillah menyatakan bahwa anak autisme yang mengonsumsi zat adiktif dan tidak melakukan diet akan mengalami perburukan gejala autisme seperti merontak dan hal tersebut berdampak pada interaksi anak autisme itu dengan orang tua dan saudara kandung. ${ }^{5}$ Kaunang ${ }^{6}$ memaparkan bahwa ketidakmampuan anak autisme merespons terhadap minat emosi dan perasaan orang lain merupakan hambatan yang menimbulkan gangguan berupa depresi dan menyebabkan anak autisme merontak.

\section{Dinamika Kasus 2 dan Bahasan}

DR berasal dari keluarga yang berkecukupan. Ayahnya ialah seorang dokter dan ibunya ialah seorang pegawai negeri sipil. Interaksi DR dengan kakaknya baik. Dalam keluarga tidak ada yang mempunyai gejala seperti yang dialami oleh DR. Interaksi dengan kakaknya sangat baik. Kadang saat kakaknya meminta tolong untuk mengambilkan suatu barang, DR sudah tahu mana yang harus diambil. Begitu juga ketika ibunya mengajak DR ke ibadah dia tidak merontak. Kadang saat DR bermain dengan teman-teman sekompleks perumahan, DR hanya diam dan melihat-lihat saja serta tidak merontak sama sekali. Kalaupun DR merontak pasti karena ia memakan coklat, tetapi saat dia mulai merontak ayahnya akan mengajak DR keliling kompleks perumahan dengan menggunakan motor karena jika tidak DR akan memukul-mukul kakaknya; kejadian seperti ini tidak sering 
terjadi di dalam keluarga ini. Interaksi di dalam keluarga ini dapat dikatakan baik karena pola asuh orang tua yang tepat serta orang tua dari DR sangat kooperatif dalam mencari tahu apa yang terjadi pada anaknya, sehingga interaksi yang terjadi bukanlah interaksi yang menyimpang seperti orang tua memukul anaknya atau menghukum anaknya dengan keras.

Perkembangan interaksi sosial pada anak autisme juga dihubungkan dengan pendidikan orang tua. Pendidikan mempunyai peran penting untuk perkembangan anak. Semakin tinggi pendidikan, semakin mudah mereka menerima serta mengembangkan pengetahuan untuk meningkatkan produktifitas yang pada akhirnya akan meningkatkan kesejahteraan keluarga. Pendidikan orang tua yang tinggi akan lebih mudah menerima informasi, mudah merubah perilaku serta mudah memberikan keputusan dalam mendidik anak dan akan berdampak baik juga pada interaksi anak tersebut dengan orang tua dan saudara kandung.

\section{Perbandingan antara Kedua Kasus}

Pada kasus pertama, keluarga SP termasuk keluarga yang memiliki tingkat pendidikan rendah dan berekonomi rendah. Tingkat pendidikan merupakan faktor yang memengaruhi interaksi seorang anak. Pada kasus ini interaksi anak suka menangis tiba-tiba karena ternyata orang tua tidak tahu tentang diet anak autisme yang menyebabkan anak memakan makanan yang membuat gejala semakin menjadi salah satunya interaksi SP yang menangis secara tiba-tiba. ${ }^{7}$

Pada kasus kedua, keluarga DR termasuk keluarga berada, serta kedua orang tuanya berpendidikan tinggi yaitu ayahnya seorang dokter dan ibunya seorang pegawai negeri sipil. Orang tua DR sangat kooperatif dalam mencari tahu apa yang terjadi pada anaknya, sehingga interaksi yang terjadi bukan interaksi yang menyimpang. Interaksi pada anak autisme bisa dipengaruhi oleh banyak hal, salah satunya pendidikan orang tua. Interaksi anak autisme yang mengamuk, berontak, menca- kar dan menyimpang lainnya bisa ditangani bila pola asuh dari orang tua yang benar dan tidak menyalah-artikan tindakan menyimpang anaknya itu. Pola asuh orang tua bergantung dari tingkat pedidikan orang tua serta tindakan kooperatif dari orang tua itu sendiri. Ketidaktahuan orang tua akan memicu dan memperberat gejala pada anak autisme seperti interaksinya yang sering mengamuk. $^{7}$

\section{SIMPULAN}

Berdasarkan hasil penelitian yang dilakukan dapat disimpulkan bahwa gangguan spektrum autisme lebih banyak ditemukan pada laki-laki dibandingkan perempuan, dan terbanyak berusia 7-10 tahun.

Interaksi menyimpang antara anak autisme dengan saudara kandung dan orang tua berupa mengamuk dan menangis secara tiba-tiba.

\section{SARAN}

Pada penelitian kualitatif didapatkan bahwa kedua subjek ini ialah anak bungsu. Diharapkan untuk orang tua agar bersikap kooperatif untuk bisa lebih mencari tahu dan memahami apa yang dialami oleh anak autisme sehingga orang tua bisa memberikan pola asuh yang tepat.

Diharapkan orang tua dan kakakkakaknya agar membantu anak autisme dalam belajar berinteraksi dan tidak memarahi, memukul atau meghukumnya.

\section{DAFTAR PUSTAKA}

1. Kartika L. Perilaku menyimpang remaja ditinjau dari aspek pemahaman tentang hukum [Skripsi]. Bekasi: UNJ; 2013.

2. Muniroh SM. Dinamika resiliensi orang tua anak autis. Jurnal Penelitian Tarbiyah. 2010;7(2):1-11.

3. I Made WS. Sinopsis Psikiatri jilid dua. Tanggerang: Binarupa Aksara, 2010

4. Ma'ruf E, Prasetyo R, Rini HL. Gambaran faktor pre natal sebagai penyebab autis di Sekolah Anak Khusus Kembang Mekar Desa Kepanjen Kecamatan Jombang Kabupaten Jombang. Available from: ejurnal.stikespemkab jombang.ac.id. 2013.

5. Kaunang Th. Gangguan Autisme Diagnosis 
dan Penatalaksanaan (1st ed). Jakarta Pusat: Care Our Children, 2015.

6. Setiawan F. Pola Penanganan Autis di Yayasan Sayap Ibu (YSI) Yogyakarta [Skripsi]. Yogyakarta: Universitas Islam Negeri Sunan Kalijaga
Yogyakarta; 2010.

7. Apriastuti DA. Analisis tingkat pendidikan dan pola asuh orang tua dengan perkembangan anak. Bidan Prada. 2013;4(1);8-12. 